\title{
Inflammatory Modulation of Bronchial Epithelial Cells' Response to Lipopolysaccharide with Pretreatment by Montelukast
}

\section{Gorana Jendrisek}

Institue of Molecular Genetics and Genetic Engineering, University of Belgrade

\section{Aleksandra Nikolic}

Institute of Molecular Genetics and Genetic Engineering, University of Belgrade

Sandra Dragicevic ( $\nabla$ sandra.d@imgge.bg.ac.rs )

Instiute of Molecular Genetics and Genetic Engineering https://orcid.org/0000-0002-1602-1880

\section{Research Article}

Keywords: gene expression, inflammation, montelukast, treatment

Posted Date: April 5th, 2021

DOI: https://doi.org/10.21203/rs.3.rs-389828/v1

License: (c) (i) This work is licensed under a Creative Commons Attribution 4.0 International License.

Read Full License 


\section{Abstract \\ Purpose}

Montelukast, a leukotriene receptor antagonist, is the most prescribed non-steroidal anti-inflammatory drug used as add-on therapy at later stages of asthma to prevent disease progression. Besides its direct anti-inflammatory effect due to blocking leukotriene action, montelukast has been proposed to have secondary anti-inflammatory and anti-fibrotic properties. This study aimed to investigate the modulatory effect of montelukast on the expression of major genes involved in airway inflammation $(T N F, I L \sigma)$ and remodeling (MMP9, TGFB1) in response to lipopolysaccharide (LPS) in vitro.

\section{Methods}

Effect of montelukast on LPS-induced acute inflammation was analyzed in the immortalized cell line derived from human bronchial epithelium, BEAS-2B. The expression of selected genes was measured by quantitative real-time polymerase chain reaction $0 \mathrm{~h}$ and $24 \mathrm{~h}$ after LPS stimulation in cells pretreated with montelukast.

\section{Results}

Montelukast was found to significantly attenuate increased TNF and IL6 gene expression, has a mild effect on $M M P 9$, and has no effect on TGFB1 expression upon stimulation with LPS.

\section{Conclusion}

The results of our study indicate that that patients already using montelukast therapy would have adequate response to acute microorganism-induced inflammation. Additional anti-inflammatory effects of montelukast could be better exploited in clinical practice and modes of montelukast use should be reconsidered to improve the therapeutic approaches in asthma.

\section{Introduction}

Asthma is a heterogenous disease, characterized by complex interactions between inflammation and airway remodeling [1]. Among mediators implicated in the pathogenesis of asthma, tumor necrosis factor-alpha (TNF-a) and interleukin 6 (IL-6) are considered as key pro-inflammatory cytokines [2, 3]. In response to various stimuli, TNF- $\alpha$ and IL- 6 are secreted by bronchial epithelial cells and inflammatory cells infiltrated in airways such as macrophages, lymphocytes and mast cells [4]. The major players in airway remodeling are transforming growth factor beta 1 (TGFB1) and matrix metalloproteinase 9 (MMP-

9) [5-7]. TGFB1 is the main profibrotic mediator and its elevated level was observed in asthmatic airways [8]. It promotes subepithelial fibrosis by stimulating the expression of collagen type I and III [7]. MMP-9 
represents the major MMP in the airways, and its increased expression is considered as a marker of inflammatory-induced bronchial epithelium damage $[7,9]$.

Montelukast is the most prescribed non-steroidal anti-inflammatory drug used for asthma treatment [10, 11]. It belongs to leukotriene receptor antagonists (LTRAs), a second class of controllers that are used as add-on therapy to inhaled corticosteroids (ICSs) for the achievement of asthma control $[12,13]$. LTRAs block specific cysteinyl leukotriene receptors (cysLTRAs) on airway structural and inflammatory cells, thus preventing bronchoconstriction, mucus secretion, and edema in asthmatic lungs. These drugs also reduce the inflow of eosinophils, thereby inhibiting their effects in the airways [14]. However, studies showed that montelukast exhibits additional anti-inflammatory properties unrelated to its action as the antagonist of cysLTRAs $[15,16]$. It decreases the lipopolysaccharide (LPS)-induced production of TNF-a and IL-6 $[17,18]$. In addition, montelukast modulates expression of mediators involved in airway remodeling. It inhibits TGFB1 gene expression [19] and secretion of TGFB1 and MMP-9 proteins [20, 21]. These findings suggest that montelukast could be used as an anti-fibrotic therapeutic agent.

Although studies suggested that montelukast could be used at earlier stages of asthma to prevent disease progression, this drug is not preferred as initial therapy [22]. Together with the direct effects of LTRA, alternative anti-inflammatory and anti-fibrotic properties of montelukast would be useful in clinical practice. Therefore, in order to fully exploit the benefits of this drug, the extent of its alternative properties should be characterized better.

The aim of this study was to investigate in vitro the modulatory effect of montelukast on the expression of genes associated with airway inflammation and remodeling in response to LPS.

\section{Material And Methods}

\section{Cultivation and treatment of BEAS-2B cells}

BEAS-2B, immortalized cell line derived from human bronchial epithelium, was kindly provided (2014) by Dr. Peter Lackie (School of Medicine, University of Southampton, Southampton, UK). The state of the cells was regularly evaluated by morphology checks using microscope and performing assays for detection of mycoplasma contamination. The cells were cultivated at $37^{\circ} \mathrm{C}$ in $5 \% \mathrm{CO}_{2}$ humidified atmosphere in LHC-9 medium (Thermo Fisher Scientific, USA) supplemented with fetal bovine serum (2\%), penicillin $(10 \mathrm{U} / \mu \mathrm{L})$ and streptomycin $(10 \mathrm{ng} / \mathrm{mL})$ and subcultured after reaching $70-80 \%$ confluence.

For treatment, BEAS-2B cells were seeded in $60 \mathrm{~mm}$ cell culture dishes at a density of $8 \times 10^{5} / \mathrm{mL}$. The next day, cells were serum-starved for $1 \mathrm{~h}$ and treated with montelukast $(100 \mu \mathrm{M})$. After $1 \mathrm{~h}$, LPS $(10 \mu \mathrm{g} / \mathrm{mL})$ was added to cells in order to induce inflammation. The cells were stimulated for $2 \mathrm{~h}$ at $37^{\circ} \mathrm{C}$ and: 1 ) immediately collected and lysed for RNA extraction or 2) medium was changed, the cells were incubated for $24 \mathrm{~h}$, collected and lysed. The experiment was performed in triplicate and it included untreated cells as control, cells treated with montelukast with and without LPS stimulation, and LPS stimulated cells without montelukast pretreatment. 
Cell lysis and total RNA extraction were performed by TRI Reagent Solution (Invitrogen, USA) according to the manufacturer's protocol. The RNA concentration and quality were determined spectrophotometrically using NanoVue (GE Healthcare Life Sciences, Austria). Reverse transcription was performed using the High Capacity cDNA Reverse Transcription Kit (Applied Biosystems, USA) according to the manufacturer's protocol.

The expression of target genes was measured by quantitative Real Time Polymerase Chain Reaction (qRT-PCR) using 5xHOT FIREPol Eva Green qPCR Mix Plus (ROX) (Solis BioDyne, Estonia). Melting curve analysis was performed after each measurement to confirm the specificity of the fragments. The glyceraldehyde-3- phosphate dehydrogenase (GAPDH) was used as the endogenous control for all measurements. The sequences of primers used to replicate the transcriptional portions of all genes are given in Table 1.

Table 1

Primer sequences and lengths of gene fragments

\begin{tabular}{|c|c|c|}
\hline Gene & Primer sequence & Length of the fragment (bp) \\
\hline \multirow[t]{2}{*}{$M M P 9$} & Forward 5'-GCTCACCTTCACTCGCGTGTA-3' & \multirow[t]{2}{*}{70} \\
\hline & Reverse 5'-TCCGTGCTCCGCGACA-3' & \\
\hline \multirow[t]{2}{*}{$T N F$} & Forward 5'-CCCAGGCAGTCAGATCATCTTC-3' & \multirow[t]{2}{*}{85} \\
\hline & Reverse 5'- AGCTGCCCCTCAGCTTGA-3' & \\
\hline \multirow[t]{2}{*}{ TGFB1 } & Forward 5'-AAGGACCTCGGCTGGAAGTGG-3' & \multirow[t]{2}{*}{136} \\
\hline & Reverse 5'-CCGGGTTATGCTGGTTGTACAG-3' & \\
\hline \multirow[t]{2}{*}{ IL6 } & Forward 5'-GCAAAGAGGCACTGGCAGAA-3' & \multirow[t]{2}{*}{93} \\
\hline & Reverse 5'-GGCAAGTCTCCTCATTGAATCC-3' & \\
\hline \multirow[t]{2}{*}{ GAPDH } & Forward 5'-GTGAAGGTCGGAGTCAACG-3' & \multirow[t]{2}{*}{112} \\
\hline & Reverse 5'-TGAGGTCAATGAAGGGGTC-3' & \\
\hline
\end{tabular}

qRT-PCR was performed using 7500 Real-Time PCR System (Applied Biosystems, USA). Thermocycling conditions were the following: initial activation $95^{\circ} \mathrm{C} / 12 \mathrm{~min}, 40$ cycles: denaturation $95^{\circ} \mathrm{C} / 15 \mathrm{~s}$, annealing $60^{\circ} \mathrm{C} / 20 \mathrm{~s}$, elongation $72^{\circ} \mathrm{C} / 20 \mathrm{~s}$. All measurements were performed in triplicate and relative quantification was calculated with the $\triangle \triangle \mathrm{Ct}$ method. The gene expression of $G A P D H$ was used to normalize the relative expression of target genes, while the expression of genes in control untreated cells was used as the calibrator. 


\section{Statistical analysis}

The results were processed in Statistical Package for Social Science (SPSS, USA) software version 25.0. All data were presented as the means \pm standard deviation (SD). Differences between continuous values for independent samples were analyzed using the Independent Samples Mann Whitney $U$ test and Kruskal Wallis test. A P value $\leq 0.05$ was considered statistically significant.

\section{Results}

In order to investigate the modulatory role of montelukast on BEAS-2B cells' inflammatory response to LPS stimulation, the expression of genes involved in airway inflammation (TNF and IL6) and remodeling (TGFB1 and MMP9) was evaluated. Cells were pretreated with montelukast and then stimulated with LPS. The measurement of gene expression was performed at two time points; upon completion of LPS stimulation (first time point) and $24 \mathrm{~h}$ after that (second time point). The results showed that montelukast had no statistically significant effect on expression of $T N F$ gene in comparison to untreated cells at both time points $(P>0.05)$ (Fig. 1A). As expected, LPS significantly increased TNF gene expression relative to untreated controls, with a stronger effect at the first time point $(P=0.01)$ in comparison to the second ( $P$ $=0.029)$. It was observed that increased expression of the TNF gene in response to LPS was reduced in cells pretreated with montelukast at both time points ( $P=0.01$ and $P=0.016$, respectively).

The expression of the IL 6 gene was significantly increased in response to montelukast relative to untreated controls, with a more prominent effect of montelukast observed at the first $(P=0.008)$ then at the second time point $(P=0.029)$ (Fig. 1B). LPS significantly increased IL 6 gene expression compared to untreated controls, with a stronger effect at the first vs. the second time point $(P=0.008$ and $P=0.029$, respectively). The LPS-induced increase of IL6 gene expression was reduced in cells pretreated with montelukast at the first time point $(P=0.001)$, as well as at the second time point $(P=0.029)$. The inhibitory effect of montelukast was more pronounced at the second time point.

The expression of the MMP9 gene was slightly increased in cells treated with montelukast compared to untreated controls at both time points, but the difference was not statistically significant $(P>0.05)$ (Fig. 2A). In response to LPS, MMP9 gene expression was significantly increased only at the second time point $(P=0.029)$. This increase was reduced in cells pretreated with montelukast compared to cells treated with LPS, but statistical significance was not achieved $(P>0.05)$.

The TGFB1 gene expression upon treatment with montelukast was slightly decreased at the first time point, but this change was not scored at the second time point (Fig. 2B). Stimulation with LPS initially induced a decrease in TGFB1 gene expression, while an increase in TGFB1 gene expression was noticed after 24h. However, neither of the findings was statistically significant $(P>0.05)$. LPS-induced changes in TGFB1 gene expression were not significantly affected by montelukast at either of the time points $(P>$ 0.05). 


\section{Discussion}

The purpose of the study is to explore the potential of montelukast to be used during the initial steps of asthma therapy to prevent inflammation and remodeling, and not only as a supplement to ICSs in the later stages of the disease. The aim of our study was to investigate if the use of montelukast as a pretreatment could alleviate induced inflammation in bronchial epithelial cells. We examined the modulatory effect of montelukast on the expression of major genes involved in inflammation and remodeling in response to LPS using immortalized bronchial epithelial cell line BEAS-2B. This cell line exhibits conserved morphological and functional characteristics encountered in healthy lungs and represents a suitable model system for studying the effects of various environmental factors [23].

Since microorganisms come into direct contact with the lung epithelium and are the most common cause of inflammation and exacerbations in asthmatics, in our experimental setup we shortly stimulated the cells with LPS in order to induce acute inflammation. Cells were treated with LPS at a concentration 10 $\mu \mathrm{g} / \mathrm{mL}$ which was previously shown not to have toxic effect on BEAS-2B cells after $48 \mathrm{~h}$ of incubation [24]. The expression of $T N F, I L 6, M M P 9$, and TGFB1 genes was analyzed at the mRNA level, at two time points, to elucidate short-term and long-term effects of the acute inflammation. Pretreatment with montelukast was performed in order to understand how patients on montelukast therapy would react to acute respiratory infections.

The influence of montelukast on the expression of selected genes was examined in order to understand its effects on healthy lung tissue and how long they last. Our results showed that montelukast initially increased the expression of IL6 genes. However, this effect of montelukast was not long-acting. The observed alterations in expression of $T N F, M M P 9$ and $T G F B 1$ genes in response to montelukast were not significant. The initial decrease of TGFB1 gene expression agrees with our previous finding [19]. Montelukast was shown to prevent TGFB1 and MMP9 secretion [20,21]. It could be suggested that the influence of montelukast on the expression of these mediators most likely involves various mechanisms.

Acute inflammation was induced by LPS. The main mechanism of LPS action includes activation of $\mathrm{PI3K} /$ Akt pathway and consequently activation of NF-kB [25]. Additionally, LPS promotes inflammation in lung epithelial cells by activating MAPK signaling pathway [26]. As expected, in our study the expression of pro-inflammatory genes was significantly increased after stimulation with LPS at both time points. More pronounced effect of LPS on MMP9 gene expression was observed 24h after stimulation and this finding is in accordance with literature [27].

The influence of montelukast pretreatment on the gene expression in BEAS-2B cells in response to LPS stimulation was studied to explore the potential of better exploiting this drug in clinical practice. The results showed that montelukast significantly attenuates the LPS-increased TNF and IL6 gene expression, at both time points. Although montelukast alone induced expression of IL 6 gene, it still had inhibitory effect on LPS-induced IL6 expression, and this effect was long-term. Our results agree with previous study showing that montelukast reduces TNF- $a$ and IL-6 production upon LPS stimulation, in 
culture fluid of the peripheral blood mononuclear cells (18). This study also proposed that montelukast prevents nuclear translocation of NF-KB induced by LPS.

We observed that montelukast had long-lasting inhibitory effect on the LPS-increased MMP9 gene expression, although statistical significance was not achieved. In addition to its negative regulation of NF-KB, montelukast was suggested to affect PI3K/Akt and MAPK signaling pathways by reducing the phosphorylation of Akt kinase, MEK and Erk $[28,29]$. The modulatory effect of montelukast on MMP9 gene expression might be due to negative regulation of these mediators. On the other hand, slight LPSinduced changes in TGFB1 gene expression were not significantly affected by montelukast.

Considering that IL-6 produces local inflammatory responses, recruits leukocytes and induces antibody production, and that TNF- $a$ induces pulmonary interstitial edema, our results suggest that patients on montelukast therapy might be more protected from acute inflammation induced by respiratory infections. These patients could also be potentially protected from airway damage caused by MMP9. Patients with persistent asthma who do not respond to standard therapy with ICSs might benefit from these alternative properties of montelukast as well [30].

Therapeutic strategy in asthma tends to reduce ICSs doses due to their adverse systemic effects and find drugs that can compensate for these deficiencies [31]. Since montelukast has much less harmful effects than steroid drugs, it represents a promising candidate. However, its anti-inflammatory and anti-fibrotic potential has not been fully utilized in therapeutic approaches. Results from our study indicate that montelukast is potentially useful to alleviate inflammation in lung cells, but that it should be carefully dosed so as not to induce gene expression that would accelerate inflammatory processes. The discovery of all the mediators that could be modulated by montelukast would be of great importance for personalized therapy, especially for treatment of the patients with increased levels of these mediators in serum.

The results of our study indicate that patients already using montelukast therapy would have adequate response to acute microorganism-induced inflammation. Identification of pro-inflammatory mediators that are modulated by montelukast might lead to more effective therapeutic protocols in patients in whom these mediators are elevated. Overall, our study supports the view that montelukast, due to its additional anti-inflammatory effects, should be better exploited in clinical practice. However, clinical studies are needed to elucidate the alternative properties and potential systemic effect of montelukast. If montelukast is confirmed to show better effects when used in the initial stages of the disease, it could improve significantly the therapeutic approaches in asthma.

\section{Declarations}

Funding: This study was supported by the grant 451-03-9/2021-14/200042 of the Ministry of Education, Science and Technological Development of the Republic of Serbia. 
Conflicts of interest/Competing interests: The authors have no conflicts of interest to declare that are relevant to the content of this article.

Availability of data and material: Data are available by the corresponding author upon reasonable request.

Code availability: Not applicable

Ethics approval: Not applicable

Consent to participate: Not applicable

Consent for publication: Not applicable

\section{References}

1. Global Strategy for Asthma Management and Prevention (2020) Global Initiative for Asthma. www.ginasthma.org

2. Berry M, Brightling C, Pavord I, Wardlaw A (2007) TNF-alpha in asthma. Curr Opin Pharmacol 7:279 82. https://doi.org/10.1016/j.coph.2007.03.001

3. Poynter ME, Irvin CG (2016) Interleukin-6 as a biomarker for asthma: hype or is there something else? Eur Respir J 48:979-981. https://doi.org/10.1183/13993003.01597-2016

4. Mahajan S, Mehta AA (2006) Role of Cytokines in Pathophysiology of Asthma. Iran J Pharmacol Ther 5:1-14. Available at: http://www.bioline.org.br/pdf?pt06001

5. Duvernelle C, Freund V, Frossard N (2003) Transforming growth factor-beta and its role in asthma. Pulm Pharmacol Ther 16:181 - 96. https://doi.org/10.1016/S1094-5539(03)00051-8

6. Li H, Romieu I, Wu H, Sienra-Monge JJ, Ramírez-Aguilar M, del Río-Navarro BE et al (2007) Genetic polymorphisms in transforming growth factor beta-1 (TGFB1) and childhood asthma and atopy. Hum Genet 121:529-538. https://doi.org/10.1007/s00439-007-0337-z

7. Mattos W, Lim S, Russell R, Jatakanon A, Chung KF, Barnes PJ (2002) Matrix metalloproteinase-9 expression in asthma: effect of asthma severity, allergen challenge, and inhaled corticosteroids. Chest 122:1543-1552. https://doi.org/10.1378/chest.122.5.1543

8. Maslan J, Mims JW (2014) What is asthma? Pathophysiology, demographics, and health care costs. Otolaryngol Clin North Am 47:13-22. https://doi.org/10.1016/j.otc.2013.09.010

9. Ohbayashi H, Shimokata K (2005) Matrix metalloproteinase-9 and airway remodeling in asthma. Curr Drug Targets Inflamm Allergy 4:177-181. https://doi.org/10.2174/1568010053586246

10. Joos S, Miksch A, Szecsenyi J, Wieseler B, Grouven U, Kaiser T et al (2008) Montelukast as add-on therapy to inhaled corticosteroids in the treatment of mild to moderate asthma: a systematic review. Thorax 63:453-462. https://doi.org/10.1136/thx.2007.081596 
11. Paggiaro P, Bacci E (2011) Montelukast in asthma: a review of its efficacy and place in therapy. Ther Adv Chronic Dis 2:47-58. https://doi.org/10.1177/2040622310383343

12. Cao Y, Wang J, Bunjhoo H, Xie M, Xu Y, Fang H (2012) Comparison of leukotriene receptor antagonists in addition to inhaled corticosteroid and inhaled corticosteroid alone in the treatment of adolescents and adults with bronchial asthma: a meta-analysis. Asian Pac J Allergy Immunol 30:130-8. Available at: http://apjai-journal.org/wpcontent/uploads/2017/12/6ComparisonVol30No2June2012P130.pdf

13. Bisgaard H (2000) Role of leukotrienes in asthma pathophysiology. Pediatr Pulmonol 30:166-76 https://doi.org/10.1002/1099-0496(200008)30:2<166::AID-PPUL15>3.0.C0;2-L

14. Tamada T, Ichinose M (2017) Leukotriene Receptor Antagonists and Antiallergy Drugs. Handb Exp Pharmacol 237:153-169. https://doi.org/10.1007/164_2016_72

15. Theron AJ, Steel HC, Tintinger GR, Gravett CM, Anderson R, Feldman C (2014) Cysteinyl leukotriene receptor-1 antagonists as modulators of innate immune cell function. J Immunol Res 2014:608930. https://doi.org/10.1155/2014/608930

16. Tintinger GR, Feldman C, Theron AJ, Anderson R (2010) Montelukast: more than a cysteinyl leukotriene receptor antagonist? Sci World J 10:2403-2413. https://doi.org/10.1100/tsw.2010.229

17. Hart LA, Krishnan VL, Adcock IM, Barnes PJ, Chung KF (1998) Activation and localization of transcription factor, nuclear factor-kappaB, in asthma. Am J Respir Crit Care Med 158:1585-1592. https://doi.org/10.1164/ajrccm.158.5.9706116

18. Maeba S, Ichiyama T, Ueno Y, Makata H, Matsubara T, Furukawa S (2005) Effect of montelukast on nuclear factor kappaB activation and proinflammatory molecules. Ann Allergy Asthma Immunol 94:670-674. https://doi.org/10.1016/S1081-1206(10)61326-9

19. Dragicevic S, Milosevic K, Nestorovic B, Nikolic A (2017) Influence of the Polymorphism C-509T in the TGFB1 Gene Promoter on the Response to Montelukast Pediat. Aller Imm Pul 30:239-245. https://doi.org/10.1089/ped.2017.0770

20. Perng DW, Wu YC, Chang KT, Wu MT, Chiou YC, Su KC et al (2006) Leukotriene C4 induces TGF-beta1 production in airway epithelium via p38 kinase pathway. Am J Respir Cell Mol Biol 34:101-107. https://doi.org/10.1165/rcmb.2005-00680C

21. Langlois A, Ferland C, Tremblay GM, Laviolette M (2006) Montelukast regulates eosinophil protease activity through a leukotriene-independent mechanism. J Allergy Clin Immunol 118:113-119. https://doi.org/10.1016/j.jaci.2006.03.010

22. Nagao M, Ikeda M, Fukuda N, Habukawa C, Kitamura T, Katsunuma T et al (2018) Early control treatment with montelukast in preschool children with asthma: A randomized controlled trial. Allergol Int 67:72-78. https://doi.org/10.1016/j.alit.2017.04.008

23. Zhao F, Klimecki WT (2015) Culture conditions profoundly impact phenotype in BEAS-2B, a human pulmonary epithelial model. J Appl Toxicol 35:945-951. https://doi.org/10.1002/jat.3094

24. Verspohl EJ, Podlogar J (2012) LPS-induced proliferation and chemokine secretion from BEAS-2B cells. Pharmacology Pharmacy 3:166-177. http://dx.doi.org/10.4236/pp.2012.32024 
25. Liu T, Zhang L, Joo D, Sun SC (2017) NF-kB signaling in inflammation. Sign Transduct Target Ther 2:17023. https://doi.org/10.1038/sigtrans.2017.23

26. Tsai MJ, Chang WA, Tsai PH, Wu CY, Ho YW, Yen MC et al (2017) Montelukast Induces ApoptosisInducing Factor-Mediated Cell Death of Lung Cancer Cells. Int J Mol Sci 18:1353. https://doi.org/10.3390/ijms18071353

27. Tian X, Xie G, Ding F, Zhou X (2018) LPS-induced MMP-9 expression is mediated through the MAPKsAP-1 dependent mechanism in BEAS-2B and U937 cells. Exp Lung Res 44:217-225. https://doi.org/10.1080/01902148.2018.1493551

28. Ojaniemi M, Glumoff V, Harju K, Liljeroos M, Vuori K, Hallman M (2003) Phosphatidylinositol 3-kinase is involved in Toll-like receptor 4-mediated cytokine expression in mouse macrophages. Eur $\mathrm{J}$ Immunol 33:597-605. https://doi.org/10.1002/eji.200323376

29. Wu S, Zhu X, Jin Z, Tong X, Zhu L, Hong X et al (2015) The protective role of montelukast against intestinal ischemia-reperfusion injury in rats. Sci Rep 5:15787. https://doi.org/10.1038/srep15787

30. Fogli S, Stefanelli F, Neri T, Bardelli C, Amoruso A, Brunelleschi S et al (2013) Montelukast prevents microparticle-induced inflammatory and functional alterations in human bronchial smooth muscle cells. Pharmacol Res 76:149-156. https://doi.org/10.1016/j.phrs.2013.08.001

31. Scaife A, Miller D, Spiteri-Cornish D, Turner SW, Devereux GS, Walsh GM (2013) Inhibitory effects of Montelukast on mediator release by nasal epithelial cells from asthmatic subjects with or without allergic rhinitis. Respir Med 107(12):1859-1865. https://doi.org/10.1016/j.rmed.2013.09.006

\section{Figures}


A TNF
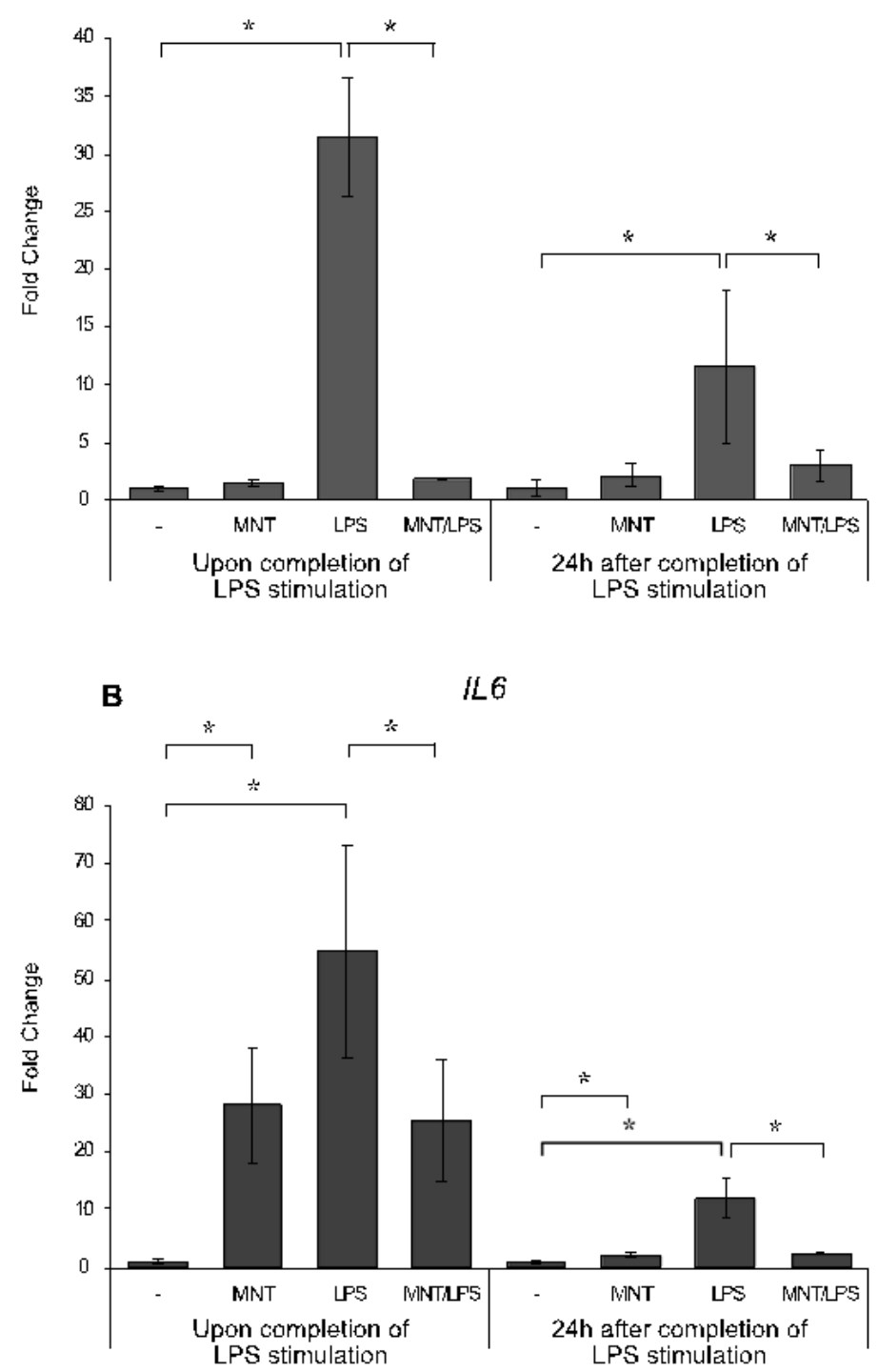

\section{Figure 1}

Effect of montelukast pretreatment on the expression of genes involved in the inflammatory response. BEAS-2B cells were subjected to indicated agents. Analysis of TNF (A) and IL6 (B) gene expression at the mRNA level was performed at two time points after LPS stimulation. GAPDH gene expression was used as endogenous control (representative of $n=3$ ) and gene expression in untreated control cells was used 
as a calibrator. Results are presented as mean \pm standard deviation. ${ }^{*} \mathrm{P}<0.05 ; \mathrm{TNF}$, Tumor necrosis factor; IL6, interleukin 6; MNT, Montelukast; LPS, Lipopolysaccharide

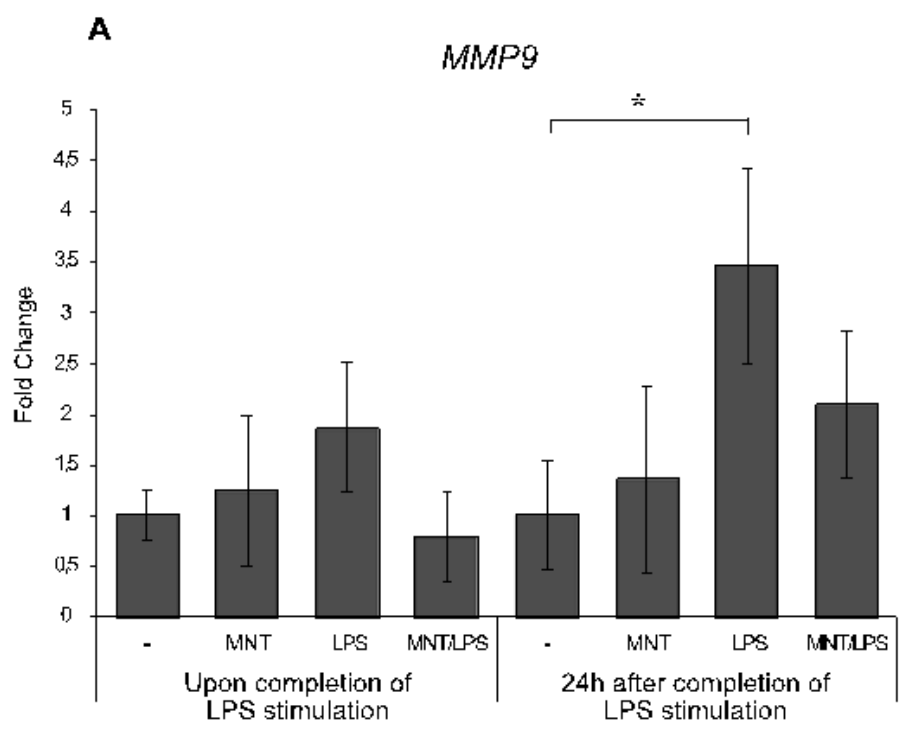

\section{B}

TGFB1

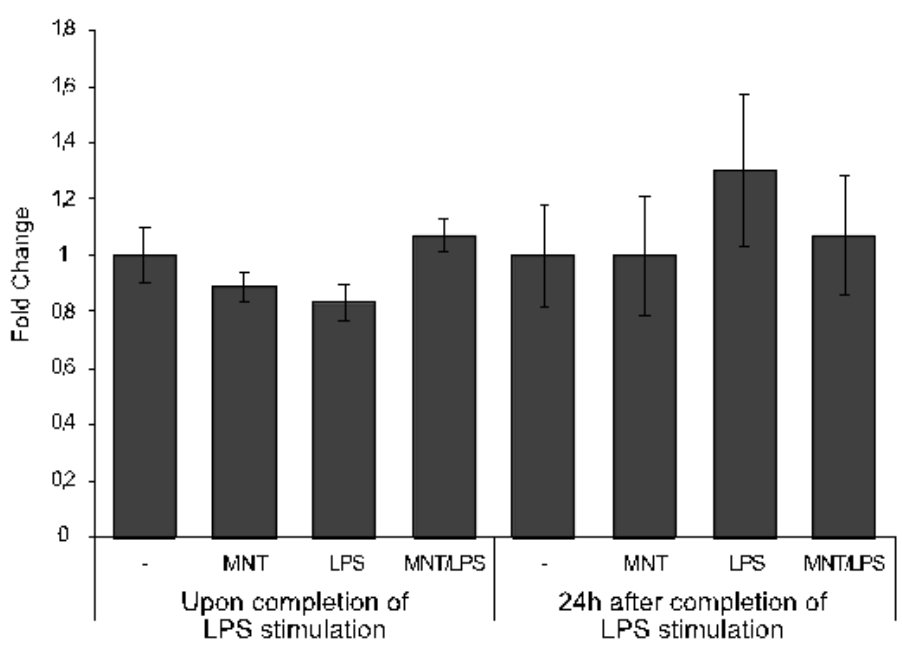

Figure 2

Effect of montelukast pretreatment on the expression of genes involved in the airway remodeling. BEAS2B cells were subjected to indicated agents. Analysis of MMP9 (A) and TGFB1 (B) gene expression at the mRNA level was performed at two time points after LPS stimulation. GAPDH gene expression was used 
as endogenous control (representative of $n=3$ ) and gene expression in untreated control cells was used as a calibrator. Results are presented as mean \pm standard deviation. ${ }^{*} \mathrm{P}<0.05$; MMP9, Matrix metaloprotenase 9; TGFB1, transforming growth factor beta 1; MNT, Montelukast; LPS, Lipopolysaccharide 